\section{CULTURAL MEANING OF CONSUMER GOODS: IMPACT OF CROSS CULTURAL VALUES ON MOTIVES FOR CONSUMING CONSPICUOUS GOODS IN SRI LANKA}

\section{A M Perera}

U K Jayasinghe-Mudalige

\section{A Patabandhige}

Sri Lanka Journal of

Economic Research Volume 2 (1)

June 2014: 21-39

Sri Lanka Forum of University Economists

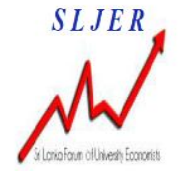

\begin{abstract}
This research examines empirically the impact of cross cultural values of Sri Lankan consumers on their motives for conspicuous consumption, which is broadly defined as "obtaining extravagance goods at higher prices to demonstrate their status and wealth to the public". The primary data collected from 225 respondents selected from four districts (i.e. Hambantota, Nuwara Eliya, Puttlam, Vavuniya) to represent various ethnicities were taken up with a number of multivariate data analysis techniques to explore their attractiveness towards consumption of conspicuous products in terms of four types of motives, including: Conformist, Hedonic, Status, and Uniqueness. The results suggest that the demand for such products largely increases in line with the perceived scarcity of the product, and there exists a greater variability amongst different ethnic groups with regard to their perception towards conspicuous consumption.
\end{abstract}

Key Words: Conspicuous consumption, Conspicuous motives, Cross culture, Cultural values

JEL Codes : $C 12, D 11, D 12, D 91, E 22$

\title{
A M Perera
}

Wayamba University of Sri Lanka, Kuliyapitiya, Sri Lanka

Telephone: +9471 4411470, email: methsila240@yahoo.com

\section{U K Jayasinghe-Mudalige}

Wayamba University of Sri Lanka, Makandura, Gonawila (NWP), Sri Lanka

Telephone: +94713628911, email: udith@ hotmail.com

\section{A Patabandhige}

University of Kelaniya, Kelaniya, Sri Lanka

Telephone: +94773637407 


\section{INTRODUCTION}

All consumers are not identical, and thus, it is possible to observe differences in consumer behavior among the members of different societies. One of the foremost reasons for differences in consumption is that all aspects of consumer behavior are culturally-bound. The well-known marketing guru, Philip Kotler (1998) states that;

"consumer buying decisions are often affected by factors that are outside of their control but have direct or indirect impact on their consumption... one example of this is cultural factors... the average consumption decisions attributed to different values by societal members reflect the fundamental thrust of their shared enculturation" (p. 46).

Moreover, the existing literature proposes that the people in different cultures have different value orientations, and these cultural value orientations may cause variations in preference for products and brands, in particularly which are more visible in nature (Allen et al, 2004; Allison, 2008; Gupta, 2010; Jai-Ok Kim, 2002). Therefore, it is sensible to take a closer look at this literature and explore the relationship, if any, between the motives for consumption of conspicuous products and the cross cultural value orientations of Sri Lankan consumers.

This research focuses on the impact of cross cultural values of Sri Lankan consumers on their motives for consumption of conspicuous products. In particularly, it investigates as to why people engage in conspicuous consumption and explores whether, and the extent to which, different cultural value orientations have influenced conspicuous consumption by varying degrees. Moreover, it examines the impact of different cultural attributes of consumer (i.e. Power Distance, Individualism, Masculinity, Uncertainty Avoidance, and Time Orientation) on their desire to exhibit social status through conspicuous consumption.

\section{LITERATURE REVIEW}

\section{Conspicuous Consumption - Concepts \& Definitions}

Conspicuousness is explained in the literature as a function of a few constructs and is generally referred as the social and public visibility surrounding the consumption of a certain product or service. When merging the notions of "conspicuousness" and "consumption" together, consumers often think of expensive brands, conspicuous luxury and spectacular extravaganza. Consequently, scholars recognize conspicuous consumption as "obtaining extravagance goods at higher prices to demonstrate their status and wealth to the public" (Page, 1992; Heaney et.al, 2005; Mason, 1983; Sofia, 2008; Sundie et.al, 2010). A very similar but more colloquial term is "keeping up with the Joneses". 
The literature on conspicuous consumption originates with Thorstein Veblen's work on 'conspicuous consumption' and Duesenberry's 'relative income hypothesis' (Veblen, 1994 [1899]; Duesenberry, 1949). Veblen (1899) used the term conspicuous consumption, for the first time his seminal work titled as "The Theory of the Leisure Class," to explain the lavish spending on goods and services that are acquired mainly for the purpose of displaying buyer's social status of a new upper class of Americans that emerged in the $19^{\text {th }}$ century. Accordingly, Veblen (1899) provides a comprehensive and broader definition on conspicuous consumption as:

"lavish spending on goods and services acquired mainly for the purpose of displaying income or wealth... and people purchase these goods with motives of 'invidious comparison' (a higher class consumes conspicuously to distinguish himself from members of a lower class) and 'pecuniary emulation' (occurs a lower class consumes conspicuously so that he will be thought of as a member of a higher class)".

Besides the cheerful consumer behaviors in capitalistic culture, Veblen observed the flaunting of luxury possessions had occurred across societies and epochs. Egyptian pharaohs, for example, displayed their wealth with golden thrones, elaborate artworks, and giant pyramids; Incan potentates dwelled in immense palaces surrounded by gold; and Indian maharajahs built extravagant and ostentatious palaces and kept collections of rare and exotic animals on their expansive estates (Sundie at el, 2010). To Veblen, these lavish spending was symptomatic of the superfluous life-style of the rich. He argued that:

"wealthy individuals often consume highly conspicuous goods and services in order to publicize their wealth, thereby achieving greater social status. In their striving for status, individuals purchase some commodities, such as jewelry, that serve no other purpose than to demonstrate wealth" (p.53)

Veblen identifies two main ways in which an individual can display wealth: through extensive leisure activities and through lavish expenditure on consumption and services. Hence, he proposed that wealthy individuals often consume highly conspicuous goods and services in order to advertise their wealth, thereby achieving greater social status. Such consumption goods must be both 'wasteful' and visible in order to please 'the observers whose good opinion is sought' (Veblen, 1994, p. 69).

Based on the modernized work of Veblen, Duesenburry (1949) claims that there is a dichotomy of absolute versus relative income and/or consumption, and argues that consumption and savings behavior are affected by concerns of social standing. He says that human well-being is a function of both the amount and types of goods affordable in 
comparison to others. Accordingly, Duesenberry developed his own theory which is labeled as "demonstration" or 'bandwagon' effect. He confirmed that the less well-off are consuming the same goods as the rich, and therefore have low or dis-savings which then lowers the average national savings rate. Researchers called this effect as the "relative income hypothesis" or the "Duesenberry effect". Alongside with Duesenberry's (1949) contribution, Leibenstein (1950) extended the general category of conspicuous consumption into three specific sub-classifications depending on the consumer's signaling intent and identified three principal external effects; (a) "Veblen" effect (where quantity demanded for a good may increase with price), (b) "Snob" effect (other's demand reduces own demand), and (c) "Bandwagon" effect (other's demand increases own demand).

\section{Motives for Conspicuous Consumption}

Motives for conspicuous consumption can be categorized into four different motives, such as: (1) Conformity motive; (2), Uniqueness motive; (3), Hedonic motive, and (4) Status motive, and are briefly described, in turn:

\section{a). Conformist Motives}

The conspicuous goods that people consume may signify the social class that they belong to. For this reason, consumers usually attempt to eradicate the confusion between what they consume and what it indicates to the others. Supporting this argument, Jaramillo \& Moizeau's (2003) stated that:

\footnotetext{
"in high-standing classes, parents spend a significant amount of money on social events in order to ensure that their child meets someone from the same social class" (p.2).
}

\section{b). Uniqueness Motives}

Affluent people buy expensive products to show their richness to the public by which they "distinguish themselves from the poor". Christine (1992) says that the very rich refuse to purchase mass promoted and merchandised products, and instead only buy products for which they are the exclusive market. This phenomenon was theoretically explained by Veblen in 1899. He used the word 'invidious comparison' which refers to situation in which a member of a higher class consumes conspicuously to distinguish himself from members of a lower class.

\section{c). Status Motives}

There are two values of consumers, i.e. self-directed values, and social affiliation values. Social affiliation values are largely fulfilled by consumers through publicizing their fashionable consumption to society. O'Cass \& McEwen, (2004) believe that the socially oriented motive is an important aspect in explaining the whole picture of conspicuous consumption, and they argue that: 
“.., consumers' interpersonal influence and social status demonstration are the two main variables in the context of conspicuous consumption" (p.28).

\section{d). Hedonic Motives}

Some scholars accept that conspicuous consumption is used by consumers to reflect their household's economic position relative to a reference group to exchange friendship, and to strengthen their social interactions. For instance, Katja \& Stuart (2012) argue that:

"as a result of peer pressure and the importance of conformity among adolescents, consuming conspicuously is essential for social acceptance, gaining and maintaining friendships and thus self-esteem” ( $p 1)$.

\section{Cultural Value Orientations}

People from different countries and different regions within the same country may differ in culture. Cultures too differ along major value dimensions which provide ways to understand how people make their consumption choice, how people behave across different cultures, how they develop social relationships and what perceptions they develop of others (Solomon, 1994).

Geert Hofstede (1980), the most recognized researcher in cultural studies, has identified five value dimensions on which cultures can be classified and compared that facilitates to understand the basic value differences: individualism-collectivism (the relationship between the self and groups), high-low uncertainty avoidance (the tolerance for uncertainty), large-small power distance (the acceptance of power inequality), masculinity-femininity (the distribution of gender roles), and long-term versus shortterm orientation (or Confucianism dimension).

a) Power Distance - Small vs. large power distance (PDI) - Power Distance means the extent to which less powerful members of society accept and expect that power is distributed unequally. Therefore, this refers to the degree of inequality that exists - and is accepted - among people with and without power. A high PDI score indicates that society accepts an unequal distribution of power and people understand "their place" in the system. Low PDI means that power is shared and well dispersed. It also means that society members view themselves as equals.

b) Individualism - Individualism vs. collectivism (IDV) - This refers to the strength of the ties people have to others within the community. A high IDV score indicates a loose connection with people. In individualist cultures, people are expected to develop and display their individual personalities and to choose their own affiliations. In collectivist cultures, people are defined and act mostly as a member 
of a long-term group, such as the family, a religious group, an age cohort, a town, or a profession, among others.

c) Masculinity - Masculinity vs. femininity (MAS) - This refers to how much a society sticks with, and values, traditional male and female roles. High MAS scores are found in countries where men are expected to be tough, to be the provider, to be assertive and to be strong. If women work outside the home, they have separate professions from men. Low MAS scores do not reverse the gender roles. In a low MAS society, the roles are simply blurred. This dimension is often renamed by users of Hofstede's work, e.g. to Quantity of Life vs. Quality of Life.

d) Uncertainty Avoidance Index - Weak vs. strong uncertainty avoidance (UAI) This relates to the degree of anxiety society members feel when in uncertain or unknown situations. In cultures with strong uncertainty avoidance, people prefer explicit rules (e.g. about religion and food) and formally structured activities, and employees tend to remain longer with their present employer. Hence, high UAIscoring nations try to avoid ambiguous situations whenever possible. They are governed by rules and order and they seek a collective "truth". In cultures with weak uncertainty avoidance, people prefer implicit or flexible rules or guidelines and informal activities. Low UAI scores indicate the society enjoys novel events and values differences.

e) Long Term Orientation - Long vs. short term orientation (LTO) - This refers to how much society values long-standing - as opposed to short term - traditions and values. This is the fifth dimension that Hofstede added in the 1990s after finding that Asian countries with a strong link to Confucian philosophy acted differently from western cultures. In long term oriented societies, people value actions and attitudes that affect the future: persistence/perseverance, thrift, and shame. In shortterm oriented societies, people value actions and attitudes that are affected by the past or the present: normative statements, immediate stability, protecting one's own face, respect for tradition, and reciprocation of greetings, favors, and gifts.

However, support is not universal for Hofstede's conceptualization, with a number of scholars critical of the reliance on Hofstede's dimensions of culture in cross-cultural research. These criticisms are largely focused on the representativeness of the sample, the validity of the claims made by the application of the dimensions, and the ethnocentrism of the items used to measure the dimensions. The most troubling criticism arises from Hofstede himself who states that:

"Obviously, these items from the IBM questionnaire do not totally cover the distinction between...in society. They only represent the issues in the IBM research that relate to this distinction", (Hofstede 1991 p. 52). 
Despite the problems associated with, researchers do recognize the usefulness of a set of culture measures proposed by Hofstede for the comparison of cultures. Therefore, most of the subsequent studies in marketing rely on Hofstede's cultural value dimensions and differences in behaviour, beliefs, and preferences are then recognized.

\section{METHODOLOGY}

The research philosophy depends on the way a researcher conceptualizes the study. This research is conceptualized in both induction and deduction approaches. Accordingly, the research hypotheses were advanced based on the literature and were tested to check whether they are capable of explaining the facts. Based on this comprehensive review of literature, the conceptual model was developed.

\section{Figure 1: Proposed Model of Cultural Value Influence the Consumption of Conspicuous Products}

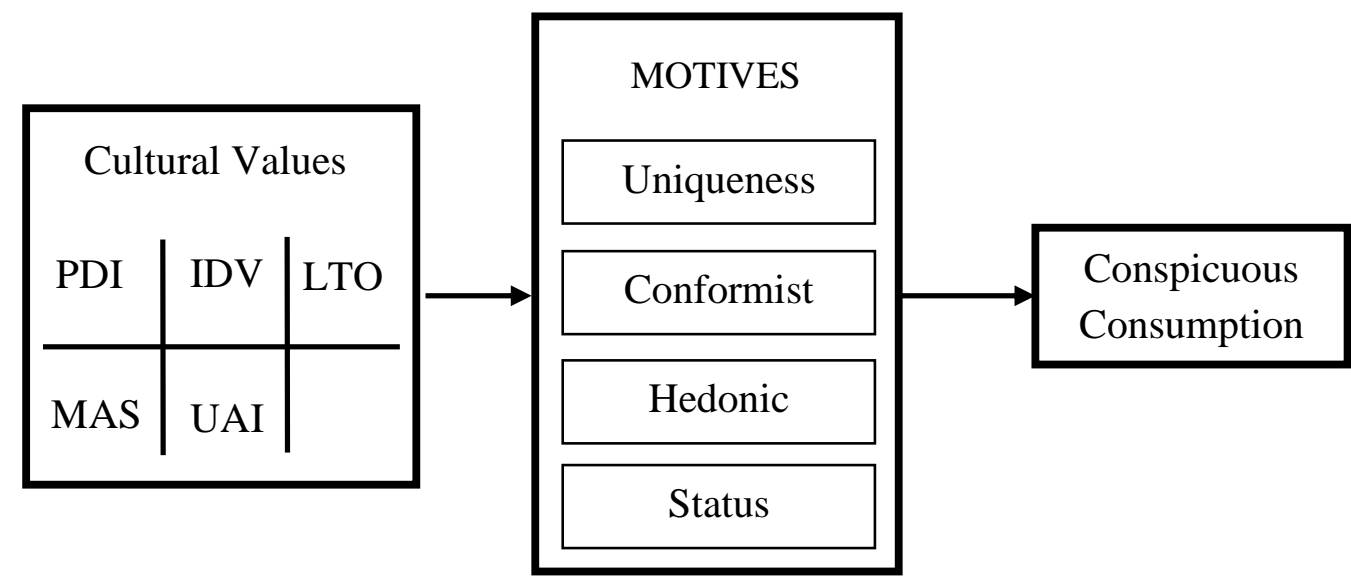

Based on the model proposed for this study, following hypotheses are developed.

$\mathbf{H}_{1}$ : There will be a significant relationship between an individual's status motive for conspicuous consumption and his/her PDI, IDV, and MAS

$\mathbf{H}_{2}$ : There will be an insignificant relationship between an individual's status motive for conspicuous consumption and his/her UAI and LTO

$\mathbf{H}_{3}$ : There will be a significant relationship between an individual's uniqueness motive for conspicuous consumption and his/her PDI, MAS, IDV, and LTO

H4: There will be a significant and positive relationship between an individual's hedonic motive for conspicuous consumption and his/her PDI and IDV

H5: There will be an insignificant relationship between an individual's hedonic motive for conspicuous consumption and his/her MAS, UAI and LTO

H6: There will be a positive and significant relationship between an individual's conformist motive for conspicuous consumption and his/her IDV, and MAS

H7: There will be an insignificant relationship between an individual's conformist motive for conspicuous consumption and his/her UAI and LTO 


\section{DATA COLLECTION}

Both primary and secondary data sources were utilized for eliciting information on the issues investigated. A questionnaire-based survey was executed to gather primary data from the selected sample. Before developing the research questionnaire, a few Focus Group Discussions were carried out to conceptualize the conspicuous consumption behaviour among different ethnic groups in Sri Lanka. The semi-structured questionnaire used to collect data for this study consists of three sections, which were developed independently. While Section "A" measured a number of demographic variables of the respondents, Section B was designed to measure consumer motives for the consumption of conspicuous products. The purpose of the items contained in Section $\mathrm{C}$ was to assess cultural value orientation of the respondents. The reliability and construct validity of questions was also measured. The Cronbach's Alphas of the dimensions were all above 0.6 , which indicated high reliability.

Data were collected from 225 respondents selected from four districts in Sri Lanka, including: Hambantota, Nuwara Eliya, Puttlam, and Vavuniya. These five districts were selected to accommodate the main four ethnic groups living in Sri Lanka, namely Sinhalese $(\mathrm{N}=100)$, Muslims $(\mathrm{N}=50)$, Indian Tamils $(\mathrm{N}=25)$, and Sri Lankan Tamils $(\mathrm{N}=50)$. Accordingly, the sample designing process contained several steps. Based on the 2001 census, initially, all the districts were ranked in descending order according to the composition of different ethnic groups. Five districts were then selected from each list. Out of these five districts, one district from each list was selected randomly.

The semi-structured questionnaire used to collect data for this study consisted of three sections; Section A (demographic characteristics of the respondents), B (motives for conspicuous consumption), and C (cultural value dimensions). The development of each section was done independently. The overall size of the survey instrument and time that potential respondents would spend completing the instrument was a concern at all stages of the development process.

The analysis of data was guided by the broad propositions of the conceptual framework presented in above. Few statistical techniques, such as one sample $T$ test, ANOVA, correlation analysis and regression analysis, were used with respect to the analysis of the motives for consuming conspicuous products items, and cultural orientation items measured by Section B and Section C of the survey. Further, a range of descriptive statistics were also employed for exploring the demographic characteristic data contained in Section A, of the survey questionnaire.

\section{RESULTS AND DISCUSSIONS}

It was observed that the male respondents were dominant in the sample (56\%). A considerable unequal distribution of gender can be seen among Muslim respondents, 
where $72 \%$ were male. $41 \%$ of the total sample represents the 25 to 34 age group and just over $22 \%$ falls in the range of 15 to 24 years old.

The respondents' attractiveness towards conspicuous consumption was measured in four aspects: conformist, hedonic, status and uniqueness motives, based on the 5-point Likert scale (where $1=$ least attractive and $5=$ most attractive). The results, given in Table 2, indicate that the means of conspicuous consumptions among different ethnicities are statistically and significantly different $(p=<.001)$. Therefore, it can be concluded that the average perceptions towards conspicuous consumption amongst these ethnic groups are considerably different.

Table 1: Conspicuous Consumption in different ethnicities

\begin{tabular}{lrrrrrl}
\hline & SN & INT & SLT & MS & F & Sig \\
\hline Mean & 3.603 & 2.746 & 3.358 & 3.110 & \multirow{2}{*}{401.05} & .000 \\
SD & .405 & .536 & .400 & .493 & & \\
\hline
\end{tabular}

\section{Motives of Conspicuous Consumption}

The significant differences found amongst the different ethnic groups for conspicuous consumption stresses the importance of exploring the motives of these groups to consume conspicuously.

Twenty-item scale (20 statements) was included in the questionnaire reflecting conspicuous consumption motives on which the respondents were asked to indicate their preferences on a Likert scale ranging from 1 (totally disagree) to 5 (totally agree). Factor analysis performed on the responses indicated that the responses clearly loaded on to four factors. The Kaiser-Meyer-Olkin (KMO) measure of sampling adequacy and Bartlett's test of sphericity for testing the adequacy of the sample were performed accordingly. Table 3 provides a summary of KMO measures and Bartlett's Test.

As per the results, the KMO measure of sampling adequacy was 0.841 , well in excess of the minimum of 0.5 recommended by Hair et.al, (2006). Bartlett's test of sphericity resulted in a Chi-Square of 14,106.38 indicating this is statistically significant at 0.001 level. The Goodness-of-Fit test resulted in a Chi-Square of 1,192.23, also statistically significant at the 0.001 level demonstrating that it was appropriate to perform a factor analysis. The Maximum Likelihood Method with Varimax Rotation was conducted to measure the interpretability of factors. A cut-off of 0.40 was applied for the Factor Loadings, as this is generally seen as signalling a high enough correlation coefficient of the item with the factor. 
Table 2: Kaiser-Meyer-Olkin Measure (KMO) and Bartlett's Test

\begin{tabular}{lcr}
\hline KMO Measure of Sampling Adequacy & & .841 \\
\hline Bartlett's Test of Sphericity & Chi-Square & $14,106.38$ \\
& df & 190 \\
& Sig. & .000 \\
\hline Goodness-of-fit Test & Chi-Square & $1,192.23$ \\
& df & 100 \\
& Sig. & .000 \\
\hline
\end{tabular}

When the un-interpretable factors and the offending items were removed from analysis only four factors remained that possess at least three items with significant factor loadings. Consequently, a four-factor solution was used for subsequent refinement of the factor solution.

The one-way analysis of variance (ANOVA) is used to determine whether there are any significant differences between the means of different motives after the Factor Analysis. Table 4 provides some very useful descriptive statistics, including the mean, standard deviation for each ethnic group and the overall sample. A positive $t$-statistic represents a relatively high orientation towards the construct and a large $t$-statistic implies that the coefficients of UM, SM, HM, \& CM were able to be estimated with a fair amount of accuracy. Moreover, there was a statistically significant difference between ethnicities in conspicuous consumption as shown in one-way ANOVA $(F=401.053, p=.000)$.

\section{Cultural Orientation of Respondents}

Section $\mathrm{C}$ of the questionnaire consists of a 20 item scale developed by Oliver et al. (2000) to measure the consumers' cultural orientation, based on Hofstede's (1980) cultural value dimensions. To measure the respondents' cross cultural values, a 'four factor solution' was used for subsequent refinement of the factor solution. Two regression analyses were conducted using conspicuous consumption (CC) as the dependent variable and the four cultural value dimensions as explanatory variables (PDI, IDV, MAS, UAV, and LTO), which were reconstructed based on the findings contained in final rotated factor matrix.

The derived factors presented in Table 5 appear to be clearly distinct from one another. The change in $R^{2}$ from the stepwise method to the enter method is only 0.05 . This confirms that multicollinearity is not present between the derived luxury consumption motivation factors. 
Table 3: Means, T-Test and ANOVA for the Motives

\begin{tabular}{|c|c|c|c|c|c|}
\hline \multirow{2}{*}{\multicolumn{2}{|c|}{ Nationality }} & \multicolumn{4}{|c|}{ Conspicuous Motives } \\
\hline & & $\begin{array}{c}\text { Uniqueness } \\
\text { Motive }\end{array}$ & $\begin{array}{l}\text { Status } \\
\text { Motive }\end{array}$ & $\begin{array}{c}\text { Hedonic } \\
\text { Motive }\end{array}$ & $\begin{array}{l}\text { Conformist } \\
\text { Motive }\end{array}$ \\
\hline \multirow{5}{*}{ Sinhalese } & Mean & 328 & 289 & 348 & 20 \\
\hline & & & & & \\
\hline & Deviation & .789 & .943 & .692 & .794 \\
\hline & $T$ & 132.59 & 97.81 & 160.80 & 103.74 \\
\hline & sig. (2-tailed) & .000 & .000 & .000 & .000 \\
\hline \multirow[t]{4}{*}{ Muslims } & Mean & 2.98 & 2.82 & 3.27 & 2.65 \\
\hline & $\begin{array}{l}\text { Std. } \\
\text { Deviation }\end{array}$ & .896 & .729 & .634 & .434 \\
\hline & $t$ & 78.68 & 88.02 & 126.38 & 138.50 \\
\hline & sig. (2-tailed) & .000 & .000 & .000 & .000 \\
\hline \multirow{4}{*}{$\begin{array}{l}\text { Tamils } \\
\text { (SL) }\end{array}$} & Mean & 3.48 & 3.31 & 3.38 & 3.51 \\
\hline & $\begin{array}{l}\text { Std. } \\
\text { Deviation }\end{array}$ & .621 & .651 & .590 & .607 \\
\hline & $t$ & 102.64 & 93.06 & 104.90 & 105.65 \\
\hline & sig. (2-tailed) & .000 & .000 & .000 & .000 \\
\hline \multirow[t]{4}{*}{$\begin{array}{l}\text { Tamils } \\
\text { (IN) }\end{array}$} & Mean & 3.33 & 3.10 & 3.53 & 3.08 \\
\hline & $\begin{array}{l}\text { Std. } \\
\text { Deviation }\end{array}$ & .760 & .848 & .787 & .786 \\
\hline & $t$ & 90.59 & 75.49 & 92.63 & 81.10 \\
\hline & sig. (2-tailed) & .000 & .000 & .000 & .000 \\
\hline \multirow[t]{4}{*}{ Total } & Mean & 3.21 & 3.02 & 3.42 & 2.87 \\
\hline & $\begin{array}{l}\text { Std. } \\
\text { Deviation }\end{array}$ & .817 & .867 & 689 & .783 \\
\hline & $t$ & 191.90 & 164.11 & 242.36 & 172.45 \\
\hline & sig. (2-tailed) & .000 & .000 & .000 & .000 \\
\hline \multirow[t]{2}{*}{ ANOVA } & $\mathrm{F}$ & 53.93 & 56.94 & 16.47 & 222.02 \\
\hline & sig. (2-tailed) & .000 & .000 & .000 & .000 \\
\hline
\end{tabular}

The mean scores on the four motivational factors were also calculated along with $t$-tests based on the whole sample and for each nationality separately. A positive $t$-statistic represents a relatively high orientation towards the construct. The results indicate that there was a statistically significant difference between Sinhalese, Muslims, Indian Tamils, and Sri Lankan Tamils in terms of their cultural value orientations ( $F=36.40, p$ $=0.000)$. The Multivariate Tests shows that there was a statistically significant 
difference in cultural value orientations based on respondents ethnicity $(F=70.06, p<$ .0005 ; Wilk's $\Lambda=0.663$, partial $\eta^{2}=.128$ ). Therefore, it can be concluded that these respondents' cultural value orientations were significantly dependent on respondents nationality $(p=.000)$.

Table 4: Regression Analysis - Multicollinearity Test for Cultural Value

\begin{tabular}{|c|c|c|c|c|c|c|}
\hline $\begin{array}{l}\text { Dependent } \\
\text { Variable }\end{array}$ & Predictor Variable & $\beta$ & $\begin{array}{c}\text { Std. } \\
\beta\end{array}$ & $\mathrm{t}$ & Sig & $\begin{array}{c}\mathrm{R}^{2} \\
\text { (Model) }\end{array}$ \\
\hline \multirow{2}{*}{$\begin{array}{l}\text { Conspicuous } \\
\text { Consumption }^{\mathrm{a}}\end{array}$} & (Constant) & 2.794 & & 36.640 & .000 & .134 \\
\hline & $\begin{array}{l}\text { Long-Term Orientation } \\
\text { (LTO) }\end{array}$ & .122 & .134 & 6.595 & .000 & \\
\hline \multirow{6}{*}{$\begin{array}{l}\text { Conspicuous } \\
\text { Consumption }^{\mathrm{b}}\end{array}$} & (Constant) & 2.964 & & 28.649 & .000 & .184 \\
\hline & Power Distance (PDI) & -.031 & -.053 & -2.471 & .014 & \\
\hline & Individualism (IDV) & .021 & .040 & 1.863 & .063 & \\
\hline & Masculinity (MAS) & -.063 & -.107 & -5.103 & .000 & \\
\hline & $\begin{array}{l}\text { Uncertainty Avoidance } \\
\text { (UAV) }\end{array}$ & .032 & .039 & 1.641 & .101 & \\
\hline & $\begin{array}{l}\text { Long-Term Orientation } \\
\text { (LTO) }\end{array}$ & .093 & .103 & 4.387 & .000 & \\
\hline
\end{tabular}

${ }^{a}$ Method: Stepwise

bMethod: Enter

Combined results from the correlation analysis and the multiple regressions were used to test hypotheses relating to anticipated effects of cultural orientation on motives for conspicuous consumption. A correlation analysis investigated whether there were statistically significant relationships between derived cultural value factors and the derived conspicuous motives. The results of the Pearson product moment correlation are presented in Table 6 , in which $r$-value indicates strength and direction $( \pm)$ of the correlation. Results reveal that, sixteen of the twenty relationships were significantly correlated at the 0.01 level.

Since all $r$ values are in the range of small to medium, it implies that there are other main influences on motives for consuming conspicuous products, other than cultural orientation. It is also implied that a causality relationship among CVDs and conspicuous motives cannot be understood from this correlation analysis. Overall, these results suggest that an individual's cultural orientation may influence the motivation for consuming conspicuous products. 
Table 5: Correlation Analysis of CVDs and Conspicuous Motives Factors

\begin{tabular}{lcccccc}
\hline & & \multicolumn{4}{c}{ Cultural Value Dimensions (CVDs) } \\
\cline { 2 - 7 } & & PDI & IDV & MAS & UAI & LTO \\
\hline Status Motive & $(r)$ & $.080^{* *}$ & $.182^{* *}$ & $.192^{* *}$ & $-.136^{* *}$ & -.030 \\
& Sig. & .000 & .000 & .000 & .000 & .143 \\
\hline Uniqueness Motive & $(r)$ & $-.193^{* *}$ & $.107^{* *}$ & $.054^{* *}$ & .018 & $.105^{* *}$ \\
& Sig. & .000 & .000 & .000 & .372 & .000 \\
\hline Hedonic Motive & $(r)$ & $-.068^{* *}$ & .007 & $-.137^{* *}$ & $.132^{* *}$ & $.167^{* *}$ \\
& Sig. & .001 & .720 & .000 & .000 & .000 \\
\hline Conformist Motive & $(r)$ & .003 & $.256^{* *}$ & $.137^{* *}$ & $-.241^{* *}$ & $-.138^{* *}$ \\
& Sig. & .878 & .000 & .000 & .000 & .000 \\
\hline
\end{tabular}

**. Correlation is significant at the 0.01 level (2-tailed).

Cohen (1992) proposes that when causality cannot be implied from a correlation analysis, it is necessary to perform subsequent analyses in order to investigate the influence of independent predictors on dependent variable. Hence, a series of multiple regressions which employ the CVDs as explanatory variables and the conspicuous motives as the dependent variable were conducted in order to investigate the influence of an individual's cultural orientation on their motives for consuming conspicuous products. Linear multiple regression was conducted to assess the relative strength of cultural values on motives for consuming conspicuous products. The derived factor scores were used for conducting the analysis. The resulting beta values and $t$-statistic for this analysis are presented in Table 7 to 10 .

Table 6: Results of the impact of CVDs on Status Motives

\begin{tabular}{|c|c|c|c|c|c|}
\hline & $\begin{array}{r}\text { Unstanda } \\
\text { Coeffic }\end{array}$ & $\begin{array}{l}\text { rdized } \\
\text { ents }\end{array}$ & $\begin{array}{l}\text { Standardized } \\
\text { Coefficients }\end{array}$ & & \\
\hline & B & $\begin{array}{l}\text { Std. } \\
\text { Error }\end{array}$ & Beta & $\mathrm{t}$ & Sig. \\
\hline (Constant) & 2.355 & .158 & & 14.896 & .000 \\
\hline Power Distance [PDI] & .055 & .019 & .060 & 2.824 & .000 \\
\hline Individualism [IDV] & .109 & .018 & .129 & 6.185 & .000 \\
\hline Masculinity [MAS] & .139 & .019 & .152 & 7.418 & .000 \\
\hline Uncertainty Avoidance [UAI] & -.173 & .029 & -.136 & -5.856 & .000 \\
\hline Long-term Orientation [LTO] & .120 & .033 & .085 & 3.676 & .017 \\
\hline
\end{tabular}

$\left(F\right.$ Statistic $=37.644, p=0.000, r^{2}=0.123$, Adjusted $\left.r^{2}=0.121\right)$ 
Table 7 shows that the four explanatory variables; PDI, IDV, MAS and UAV, contribute significantly to the prediction of status motive for consuming conspicuous products. This confirms the results of the Pearson correlation in Table 06. These results were in favor of the first hypothesis $\left(\mathbf{H}_{1}\right)$, which states: a significant relationship between an individual's SM for conspicuous consumption and his/her PDI, IDV, and MAS, and therefore it is accepted. However, since a significant relationship was found between SM and UAI ( $\mathrm{p}<.001), \mathbf{H}_{2}$, which proposed an insignificant relationship between an individual's SM for conspicuous consumption and his/her UAI and LTO, was not fully supported.

Table 7: The Regression of Uniqueness Motive with CVDs

\begin{tabular}{lcccccc}
\hline & $\begin{array}{c}\text { Unstandardized } \\
\text { Coefficients }\end{array}$ & $\begin{array}{c}\text { Standardized } \\
\text { Coefficients }\end{array}$ & & \\
\hline & B & Std. Error & Beta & $\mathrm{t}$ & Sig. \\
\hline (Constant) & 2.514 & .149 & & 16.867 & .000 \\
Power Distance [PDI] & -.192 & .018 & -.222 & -10.521 & .000 \\
Individualism [IDV] & .119 & .017 & .150 & 7.203 & .000 \\
Masculinity [MAS] & .073 & .018 & .084 & 4.108 & .000 \\
Uncertainty Avoidance [UAI] & .056 & .028 & .047 & 2.011 & .044 \\
Long-term Orientation [LTO] & .112 & .031 & .084 & 3.649 & .000 \\
& & & & & \\
\hline
\end{tabular}

$\left(F\right.$ Statistic $=37.436, p=0.000, r^{2}=0.073$, Adjusted $\left.r^{2}=0.071\right)$

Results of the Multiple Regression analysis indicates that PDI, IDV, MAS and LTO contribute significantly to the prediction of uniqueness motive for consuming conspicuous products. This also confirms the results of the Pearson correlation in Table 06. $\mathbf{H}_{3}$ : hypothesised that there would be a significant relationship between an individual's UM for conspicuous consumption and his/her PDI, IDV, MAS, UAI and LTO. This hypothesis is also supported.

The results from the Multiple Regression analysis presented in Table 9 indicates that IDV, MAS, UAI and LTO contribute significantly to the prediction of hedonic motive for consuming conspicuous products. This confirms several results of the Pearson correlation presented in Table 6. 
Table 8: The Regression of Hedonic Motive with CVDs

\begin{tabular}{lccccc}
\hline & $\begin{array}{l}\text { Unstandardized } \\
\text { Coefficients }\end{array}$ & $\begin{array}{c}\text { Standardized } \\
\text { Coefficients }\end{array}$ & & \\
& B & Std. Error & Beta & t & Sig. \\
\hline (Constant) & 2.685 & .127 & & 21.123 & .000 \\
Power Distance [PDI] & -.033 & .016 & -.045 & -2.097 & .000 \\
Individualism [IDV] & .054 & .014 & .081 & 3.829 & .036 \\
Masculinity [MAS] & -.088 & .015 & -.121 & -5.856 & .000 \\
Uncertainty Avoidance [UAI] & .089 & .024 & .089 & 3.773 & .000 \\
Long-term Orientation [LTO] & .136 & .026 & .121 & 5.206 & .000 \\
& & & & & \\
\end{tabular}

$\left(F\right.$ Statistic $=26.219, p=0.000, r^{2}=0.052$, Adjusted $\left.r^{2}=0.050\right)$

$\mathbf{H}_{4}$ proposed that there would be a significant and positive relationship between an individual's Hedonic Motive for conspicuous consumption and his/her PDI and IDV. This hypothesis can be rejected, as significantly negative relationship was obtained between HM and PDI ( $p<.001)$, and insignificantly positive relationship was obtained between HM and IDV $(p=.720)$. $\mathbf{H}_{5}$, that proposed an insignificant relationship between an individual's Hedonic Motive for conspicuous consumption and his/her MAS, UAI and LTO, can also be rejected.

The results from the Multiple Regression analysis summarized in Table 10 indicate that IDV, MAS and UAI are significant predictors of conformist motive for consuming conspicuous products.

Based on these results, $\mathbf{H}_{6}$, which hypothesized that there would be a positive and significant relationship between an individual's Conformist Motive for conspicuous consumption and his/her IDV, and MAS, can be retained. Moreover, $\mathbf{H}_{7}$ which proposed an insignificant relationship between an individual's Conformist Motive for conspicuous consumption and his/her UAI and LTO, is partially supported. 
Table 9: The Regression of Conformist Motive with CVDs

\begin{tabular}{lcccccc}
\hline & \multicolumn{2}{c}{$\begin{array}{c}\text { Unstandardized } \\
\text { Coefficients }\end{array}$} & $\begin{array}{c}\text { Standardized } \\
\text { Coefficients }\end{array}$ & & \\
& $\mathrm{B}$ & $\begin{array}{c}\text { Std. } \\
\text { Error }\end{array}$ & Beta & $\mathrm{t}$ & Sig. \\
& 3.123 & .140 & & 22.274 & .000 \\
\hline (Constant) & -.022 & .017 & -.026 & -1.262 & .207 \\
Power Distance [PDI] & .151 & .016 & .199 & 9.722 & .000 \\
Individualism [IDV] & .072 & .017 & .087 & 4.308 & .000 \\
Masculinity [MAS] & -.203 & .026 & -.177 & -7.751 & .000 \\
Uncertainty Avoidance [UAI] & -.016 & .029 & -.012 & -.545 & .586 \\
Long-term Orientation [LTO] & & & & & \\
\hline
\end{tabular}

$\left(F\right.$ Statistic $=26.219, p=0.000, r^{2}=0.052$, Adjusted $\left.r^{2}=0.050\right)$

\section{CONCLUSIONS}

Based on the review of the literature pertaining to influence of individual's cultural values on motives for consuming conspicuous products, a number of hypotheses were proposed. Five dimensions of cultural values proposed by Hofstede (1980) were used to categorize the cultural orientation of respondents. Literature suggests that consumer motives for the consumption of conspicuous products could be accounted for by four forms of motives: status, uniqueness, conformist, and hedonic. Therefore, these four motives were used in this research.

The outcome of analysis indicates that Sri Lankans, in general, possess a high level of hedonic motives. Therefore, the demand for conspicuous products increases in line with the perceived scarcity of these products. Uniqueness motive observed to be the second most significant motive affecting conspicuous consumption of the respondents. It implies that respondents are motivated to consume conspicuous products to distinguish them from other consumers. Contrary to the greater importance placed on the pursuit of status as a reason for people choosing to consume conspicuously, status motive was highlighted as the third important motivating factor of conspicuous consumption while the conformist motive was identified to be the fourth important motive in this regard. It suggests that the respondents' conspicuous consumption might also be influenced by their motive for creating social opportunities and social interaction.

A greater variability was observed amongst the different ethnic groups in their perception towards conspicuous consumption. The one-way MANOVA confirmed that 
there was a statistically significant difference between the Sinhalese, Muslims, Sri Lankan Tamils and Indian Tamils in the level of importance attached to the various motives for the consumption of conspicuous products.

The outcome of both the Pearson Correlation and Multiple Regression indicate that a significant, but weak, relationship exists between power distance, individualism, masculinity, uncertainty avoidance, and status motive for the consumption of conspicuous products. These results further suggest that the power distance, individualism, masculinity, and uncertainty avoidance dimensions of cultural values are better predictors of status motive than the long-term orientation dimension of cultural values. It was confirmed that Power distance, Individualism, Masculinity and Uncertainty avoidance values of culture contribute significantly to the prediction of status motive for consuming conspicuous products. Moreover, the results established that Power distance, Individualism, Masculinity and Long-term orientation contribute significantly to the prediction of uniqueness motive of conspicuous consumption.

Where the relationship between hedonic motive for consuming conspicuous products and the cultural values of respondents were of concern, it was found that all cultural value dimensions, other than the Power distance were significantly correlated with hedonic motive of respondents. Yet, the conformist motive of consumers' was found to be significantly correlated only with Individualism, Masculinity and Uncertainty avoidance dimensions of culture.

\section{REFERENCES}

Schaefer, Allen D., Charles M. H., \& R. Stephen Parker (2004). A cross-cultural exploration of materialism in adolescents, International Journal of Consumer Studies 28(4): 399-411.

Allison, Gareth M. (2008). Mirror, mirror on the wall: culture's consequences in a value test of its own design. The Academy of Management Review 33(4): 885-904.

Chao, Angela, and Schor, J. B (1998). Empirical tests of status consumption: Evidence from women's cosmetics. Journal of Economic Psychology 19(01): 107-131.

Duensberry, James S (1949). Income, saving, and the theory of consumer behavior. Cambridge, Harvard University Press.

Gupta, Susan F (2010). Cultural value dimensions in a strategic decision making context. Monmouth University, (http://marketing.byu.edu). 
Heaney, Joo-Gim, Goldsmith Ronald E, Wan Jusoh, and Wan J (2005). Status consumption among Malaysian consumers exploring its relationships with materialism and attention-to-social-comparison-information. Journal of International Consumer Marketing 17(04): 83-98.

Hofstede, G. (1980). Culture's consequences: international differences in work related values. Beverly Hills: Sage.

Kim, Jai-Ok, Sandra F., Qingliang G., \& Sook M. (2002). Cross-cultural consumer values, needs and purchase behavior. Journal of Consumer Marketing 19 (06): 481-502.

Isaksen, Katja J. and Stuart R. (2012). The commodification of self-esteem: Branding and British teenagers. Psychology and Marketing 29(03): 117-35.

Kotler, P (2000/1998) Marketing Management $13^{\text {th }}$ ed, SAGE Publication.

Leibenstein, H., (1950). Bandwagon, Snob, and Veblen effects in the theory of consumers' demand, Quarterly Journal of Economics, Vol. 64, pp. 183-207

Mason, R.S., (1983). The economic theory of conspicuous consumption, International Journal of Social Economics, Vol. 10(03), pp 3-17

Miller, R. (2002). In-store impact on impulse shoppers, Journal of Marketing, pp. 27-28

O'Cass, A. \& McEwen, H., (2004). Exploring consumer status and conspicuous consumption, Journal of Consumer Behaviour, Vol. 4(01), (October), pp. 25-39

Page, C. (1992). A History of conspicuous consumption, Advances in Consumer Research: pp. 82-87

Sofia U.S. (2008). A consumer cultural exploration into ordinary status consumption of "home" and home aesthetics, Lund Institute of Economic Research

Solomon, M., \& Rabolt, N. (2004). Consumer behavior: In fashion, $1^{\text {st }}$ ed. Upper saddle river, NJ: Pearson Education, Inc.

Sundie, M., Kenrick, T., Griskevicius, V., Tybur, M., Vohs, D., \& Beal, J. (2010). Peacocks, Porsches, and Thorstein Veblen: conspicuous consumption as a sexual signaling system, Journal of Personality and Social Psychology

Tai Shan A.U. (2007). A study of conspicuous consumption in the Chinese automobile market. a Dissertation presented for the degree of MA Marketing, the University of Nottingham 
SLJER Volume 2 Number 1, June. 2014

Veblen, T. (1925[1899]), The theory of the leisure class: an economic study of institutions, New York: Macmillan

Veblen T. (1918). The higher learning in America, New York: The Viking Press 